\title{
COMUNICACIÓN, GUERRA Y DIPLOMACIA. LAS RELACIONES DE LOS REBELDES ESPAÑOLES Y EL EXILIO SICILIANO EN LAS GUERRAS DE NAPOLEÓN, 1808-1814
}

\author{
Pablo de la Cruz Pérez*
}

\begin{abstract}
RESUMEN
Las relaciones diplomáticas entre el reino de España y el reino de Nápoles sufren durante la segunda mitad del siglo XVIII un profundo desgaste a causa de las disputas europeas. Las contradicciones de intereses acaban por romper las relaciones de dos cortes hermanas durante la Revolución Francesa, pero ante la invasión napoleónica de Nápoles en 1806 y España en 1808, los defensores de la casa de Borbón vuelven a encontrarse junto a Inglaterra en su guerra contra Francia. En este estudio presentamos testimonios de las relaciones diplomáticas que se establecieron entre la rebelión española y el exilio siciliano durante el periodo 1808-1814.
\end{abstract}

PALABRAS CLAVE: Napoleón, Guerra de la Independencia, Decennio Francese, consulado, Emmanuelle Viale

Enviado: 19/02/2019

Aceptado: 13/07/2020

*pdelacruhe@gmail.com 


\title{
COMMUNICATION, WAR AND DIPLOMACY. THE RELATIONS OF THE SPANISH REBELS AND THE SICILIAN EXILE IN THE WARS OF NAPOLEON, 1808-1814
}

\author{
Pablo de la Cruz PéRez*
}

\begin{abstract}
During the second half of the eighteenth century, diplomatic relations between the Kingdom of Spain and the Kingdom of Naples were severely eroded by European disputes. The contradictions of interests end up breaking the relations of two sister Courts during the French Revolution, but with the Napoleonic invasion of Naples in 1806 and Spain in 1808 , the defenders of the house of Bourbon meet again alongside England in their war against France. In this study we present testimonies of the diplomatic relations that were established between the Spanish rebellion and the Sicilian exile during the period 1808-1814.

KEYWORDS: Napoleon, Penninsular War, Decennio Francese, consulate, Emmanuelle Viale
\end{abstract}

Enviado: 19/02/2019

Aceptado: $13 / 07 / 2020$

*pdelacruhe@gmail.com 
Adentrarnos en el estudio de la guerra de la Independencia en España supone la necesidad de encuadrar nuestros estudios dentro del marco internacional. Teniendo siempre presente el peso del contexto europeo y la influencia que tienen en España los enfrentamientos en el continente, podemos comprender de un modo más estructurado y completo, diacrónico y global, aquellos procesos que tienen lugar en la península ibérica ${ }^{1}$. Efectivamente, el progreso de la guerra en el interior de España entre 1808 y 1814, nos permite perfilar dos bandos con diversos de intereses, dos exponentes de estructuras de poder político, administrativo y social enfrentados: la monarquía de José I Bonaparte y los rebeldes de las juntas. Ambos bandos protagonizan un enfrentamiento al calor de la invasión francesa y de la resistencia a la misma, pero si profundizamos en nuestro análisis, existen divergencias internas en el seno de los propios bandos. Los enfrentamientos entre individuos, facciones y sensibilidades, por ejemplo, entre la Junta Central y la Regencia, o en el seno de las Cortes de Cádiz, enriquecen nuestra comprensión, pues atienden a la complejidad de los acontecimientos internos y su relación con los enfrentamientos y disputas europeas. No es aventurado entender la guerra de la Independencia de España como un apéndice de la guerra en Europa, y así fue entendida por aquellos que, como nosotros, elevamos la vista de lo específico a lo general, para comprender mejor ambas realidades.

Durante las primeras décadas del siglo XIX, tras el fracaso de las coaliciones antirrevolucionarias, la política en Europa comienza a gravitar en torno a dos grandes potencias: el Imperio francés y Gran Bretaña. Ambas se encuentran a la carrera por dirigir el destino del continente, enfrentadas por un poder hegemónico que les permita definir el presente y arbitrar el futuro de Europa, a la cabeza de dos bloques antagónicos. Los países, facciones e ideas procederán a enfrentarse dentro de un mapa dominado por franceses y británicos.

La dimensión de los procesos históricos que se desarrollan en el interior de España durante la guerra de la Independencia está absolutamente ligada al conflicto general en Europa. Así, la monarquía josefina representa el poder francés, y la rebelión, organizada en torno a las juntas y las Cortes, se alinea desde el primer momento con Gran Bretaña. No obstante, si profundizamos en el conflicto general, podemos ver que existen otros actores y que, en el plano de las relaciones exteriores, las instituciones rebeldes españolas buscaron sin descanso el reconocimiento diplomático y la ayuda

1. A. Moliner (2007), 11.

(C) Baetica. Estudios Historia Moderna y Contemporánea, 40, 2020, 195-231. Facultad de Filosofia y Letras, Universidad de Málaga. Departamento de Historia Moderna y Contemporánea 
extranjera, más allá del crucial apoyo británico, para combatir a Francia y atenuar su propio aislamiento. Desde el estallido de las hostilidades en España, Gran Bretaña se erige como principal defensor de la rebelión, pero la diplomacia de las juntas y las Cortes gaditanas no cejarán en su intento de conseguir el reconocimiento de otras monarquías como Austria, Prusia, Rusia o Turquía ${ }^{2}$. No en vano, esta labor diplomática protagonizada por los representantes rebeldes logrará el restablecimiento de tratos y relaciones con una corte hermana olvidada tiempo atrás: la corte borbónica de Nápoles, que igualmente víctima de la potencia de Napoleón se encuentra exiliada en Sicilia desde 1806 y protegida por el inverosímil aliado común que la casa de Borbón encontró en Gran Bretaña.

Volviendo sobre nuestros pasos, debemos tener presente que la Monarquía Hispánica y el virreinato napolitano comparten una historia común durante todo el periodo moderno. Los conflictos sucesorios en España y Austria durante el siglo XVIII harán de España y Nápoles dos reinos separados e independientes, pero ambos mantendrán entre sí una conexión derivada de su propia historia y de la dinastía que reinará en ambas cortes. La familia de Borbón detentó el poder en París, Madrid, Parma y Nápoles, lo que otorgó al Pacto de Familia un área de dominación e influencia más que reseñable en el conjunto europeo y americano ${ }^{3}$.

A lo largo del XVIII, las relaciones entre Nápoles y España se desarrollan a medio camino entre la cordialidad y la tensión, pero a medida que el siglo avanza, los equilibrios de poder en Europa desgastan la diplomacia entre los dos reinos, pues comienzan a vehicular en torno a intereses opuestos. España luchará por mantener a Nápoles dentro de su esfera de influencia, pero Nápoles oscilará entre la alianza del Pacto de Familia y sus relaciones con Austria e Inglaterra. A finales del siglo, las relaciones se tensarán hasta la ruptura frente al estallido de la Revolución Francesa, que colocará a España y Nápoles en lugares opuestos dentro de los sistemas de alianzas.

Tras esa ruptura, la invasión napoleónica de ambos espacios genera un contexto en el que los intereses españoles y napolitanos vuelven a encontrarse. Nápoles y España se enfrentarán a un enemigo común. Efectivamente, desde 1808 a 1814 existieron relaciones entre ambos espacios, los rebeldes españoles defendieron la legitimidad dinástica de Fernando VII al trono de

2. M. Á. Ochoa Brun (1996). L. Stampa Piñeiro (2011). M. ${ }^{a}$ V. López-Cordón Cortezo (1986), 85-106.

3. Para un estudio de la historia del Mezzogiorno italiano tenemos las obras de G. Galasso (1992), (2005), (2006), (2007) y (2008). 
España y la corte de Fernando IV de Nápoles, exiliada en Palermo, sumará sus esfuerzos a la causa española. Las relaciones existentes en este periodo entre dos espacios ligados históricamente pueden comenzar a vislumbrarse con tres acontecimientos relevantes que exponemos a continuación. En primer lugar, el viaje a la colonia británica de Gibraltar por parte de Leopoldo de Borbón, hijo de Fernando IV, y su estancia allí desde julio a noviembre de 1808, como ha estudiado y expuesto la doctora María Teresa Nava Rodríguez 4 . En segundo término, la comisión extraordinaria que en febrero de 1809 lleva a Antonio Mordella y a Joseph Febrer a Cerdeña y Sicilia, como representantes de la Junta Central y de la Junta de Valencia ${ }^{5}$. En tercer lugar, la presencia destacable de un flujo de información generado por dos cónsules sicilianos presentes en tierras españolas durante el conflicto, Marco Maquiavelli en Cádiz y Emmanuelle Viale en Gibraltar ${ }^{6}$.

Estos tres acontecimientos nos permiten indagar en la existencia de relaciones entre España y Sicilia durante el periodo bélico, y uno de los factores más interesantes es analizar cómo tales contactos se desarrollaron bajo el constante paraguas de Gran Bretaña, el aliado y protector mutuo, que durante el periodo controla las comunicaciones en el Mediterráneo. Por ello, antes de tratar los contactos entre la rebelión española y el exilio siciliano, creemos necesaria la reconstrucción del contexto en que se encuadran dichas relaciones, después de un siglo XvIII de equilibrios y tensiones que debemos tener presente. Durante el siglo de las luces, Gran Bretaña atiende a la defensa de una política de contención en el continente, defendiendo un equilibrio de poderes en Europa que mantiene a raya a Francia. Ese equilibrio, no obstante, tendrá una consecuencia secundaria: el desgaste de las relaciones entre las cortes de España y Nápoles; que procederán a conformar alianzas incompatibles entre sí, pues mientras España permanece al lado de Francia, Nápoles procederá al acercamiento a Gran Bretaña. A partir de la segunda mitad del XVIII las relaciones irán tensándose más y más, hasta que con el estallido de la Revolución francesa se rompan por

4. M. T. Nava Rodríguez (2017), 201-214.

5. Archivo Histórico Nacional (AHN), Estado, leg. 21, doc. 153. Relación del diario que con las cartas y notas de oficio han presentado a la Superior Junta de Observación y Defensa de este Reyno sus comisionados a Cerdeña y Sicilia, don Joseph Febrer y de Pedro, y don Antonio Mordella y Spotorno, por Joseph Estévan y hermanos, Valencia, 1809. AHN, Estado, leg. 48, doc. 94. Informe de José Julián, teniente de navío, sobre el traslado de los comisionados a Cerdeña y Sicilia. Alicante, a 26 de abril de 1809.

6. Archivio di Stato di Napoli (ASN), Affari Esteri, Reggio Console di Gibilterra, 18061814, leg. 2651, 2652, 2652bis. 
completo. Ahora bien, después de años de antagonismo, el imperialismo napoleónico volverá a juntar a ambas cortes en defensa de unos intereses compartidos.

Las dinámicas que subsisten en las relaciones de España con los diferentes espacios italianos, de manera más concreta con Nápoles, deben ser analizadas dentro de los cambios que experimenta el panorama general europeo desde comienzos del XVIII hasta el estallido de las guerras napoleónicas. El equilibrio europeo de Utrecht-Rastatt, punto de partida en la geopolítica del setecientos, relegaba a la nueva monarquía borbónica española a una posición subsidiaria dentro de Italia. El balance de poder orquestado en la paz de la guerra de Sucesión Española otorgaba a la corte de Viena una posición preminente en la península de los Apeninos. El abandono de la pretensión de la casa de Austria sobre Madrid se saldó con el traspaso a Viena del dominio sobre el virreinato de Nápoles, Cerdeña y el ducado de Milán, dejando la isla de Sicilia al reino de Saboya, que se asentaba al norte de Italia. La casa de Austria, fruto de la Paz de Utrecht, tomaba el relevo definitivo de la corona española en sus posesiones flamencas, que pasaron al poder del nuevo emperador, Carlos VI de Habsburgo ${ }^{7}$.

El XVIII español se presenta en términos generales condicionado por la alianza dinástica con los borbones de Paris. Un elemento crucial al que debemos sumar el desarrollo de una visión irredentista por parte hispánica, que planteará durante todo el setecientos una política con ánimo de revocar el equilibrio nacido de la derrota exterior en el conflicto sucesorio. Una derrota que acarreaba para España una posición desfavorable en Europa ${ }^{8}$. Dejando a un lado la política americana, los ejes fundamentales de la política exterior hispana abandonan en el XVIII las pretensiones anteriores sobre Flandes y las regiones del norte, aquellas que durante el XVI y el XVII ejercieron de cerco sobre Francia y que reafirmaron la presencia española en los puertos y mercados del mar del Norte y Alemania.

Madrid abandona su interés en el norte de Europa y centra su visión en el Mediterráneo, en los puertos africanos y en las antiguas posiciones

7. Sobre el Archiduque Carlos de Habsburgo, V. León SAnz (1992) y (2013), y M. Verga (1985). Sobre la proyección italiana del conflicto sucesorio, la paz de Utrecht y el sistema de equilibrio: C. Cremonini (2013), L. J. Guía Marín (2013), N. Guasti e S. Russo (2010) e G. Galasso (1970).

8. Sobre la política internacional española del XVIII, D. Ozanam (2002) y J. M. Jover ZAMORA (1999). 
italianas que han sido traspasadas a Austria en la paz de Utrecht ${ }^{9}$. Contando con la potencia francesa en el norte, las pretensiones españolas en Italia se traducen en una intervención directa en la península durante los conflictos de sucesión polaco y austriaco. El Tratado de Aquisgrán de 1748, consecuencia de la guerra de Sucesión Austriaca, será el punto de referencia político que definirá la toma de posiciones en el panorama italiano. Consolida la división de Italia e inaugura una situación de paz ininterrumpida hasta el estallido de la revolución en Francia. En términos geopolíticos, María Teresa de Austria cedió en Aquisgrán los ducados de Parma, Piacenza y Gustalla al infante Felipe de Borbón, espacios que venían a reforzar desde el norte la posición en el sur, pues el príncipe Carlos ostentaba la corona de Nápoles y Sicilia desde 1734.

Después de Aquisgrán, las disputas políticas en torno a Italia se mantendrán dentro de los cauces de la paz. Los conflictos de intereses entre actores como Austria, España o Francia se solucionarán por medio de la diplomacia y con la puesta en práctica de políticas matrimoniales que enlazan a las casas de Habsburgo y de Borbón. No obstante, como en el resto de Europa, el equilibrio fijado en Aquisgrán se desgastará poco a poco, a medida que se tensan las relaciones a causa de intereses contrapuestos y de conflictos externos. La presencia de Gran Bretaña en el Mediterráneo será un elemento de tensión crucial para las relaciones entre España y Nápoles. Gran Bretaña establece relaciones comerciales con Nápoles y encuentra afinidades políticas en la corte de Fernando IV y María Carolina de Austria, ansiosa de apartarse de la influencia española. La potencia inglesa tiene un papel determinante en el desarrollo de la política europea y mediterránea, por ello debe estudiar el desarrollo de su postura en el marco internacional.

\section{EL PAPEL DE GRAN BRETAÑA. DE LA DEFENSA DEL EQUILIBRIO A LA ESTRATEGIA CONTRA NAPOLEÓN}

Desde finales del XVII, Inglaterra comienza a actuar como un agente dispuesto a discutir las pretensiones de cualquier potencia continental en Europa. Durante el reinado de Luis XIV, para no asistir al nacimiento de un poder hegemónico en el continente, justo cuando España había dejado de serlo, Inglaterra se alinea con Holanda frente a Francia. El principio de

9. Sobre la proyección italiana: M. C. Pascerini (2016), J. A. Ferrer Benimeli (2004), A. Álvarez-Ossorio Alvariño (2004) y M. Á. Pérez Samper (2003). Sobre África, J. U. Martínez Carreras (1990). 
equilibrio definió la actuación británica en la sucesión española, permitida solo ante la estipulación previa de no unir los reinos de España y Francia bajo una misma corona, y con la compensación, que, ante una España borbónica en Europa, suponía una Italia y unos territorios flamencos dominados por la casa de Austria. Utrecht suma a las pretensiones británicas la posesión de Menorca y Gibraltar, plazas que permiten a Inglaterra adentrarse por primera vez en el Mediterráneo y controlar el estrecho, dando un paso más en la ambición inglesa por el control de los mares. Desde finales del XVII en adelante, la estrategia de Gran Bretaña consistirá en favorecer el equilibrio europeo para impedir la puesta en cuestión de su propia hegemonía en el mar, impidiendo la competencia en las colonias y en el comercio ${ }^{10}$.

La victoria británica en la guerra de los Siete Años y el tratado de Paz de París de 1763 reafirmaba esta política. Después del conflicto en el continente y en las colonias, París devolvía a Gran Bretaña la isla de Menorca y le otorgaba posesiones en las Indias Orientales, allí donde la compañía comercial albergaba factorías y colonias desde el siglo anterior. Treinta años después, el conflicto colonial abierto en la costa norteamericana fue calamitoso para los intereses de la metrópoli londinense, y la segunda Paz de París, en 1783, reconocía la independencia de las Trece Colonias que Luis XVI y Carlos III habían apoyado con entusiasmo. Después del descalabro americano, mantener la presencia en el Caribe y en el Mediterráneo será muy importante para Gran Bretaña. Tras la pérdida de las Trece Colonias, los británicos comenzarán a mirar hacia Sudamérica y Asia. Controlar el Mediterráneo será clave para las comunicaciones con el mundo árabe, para introducirse en el mercado italiano y otomano, y con el estallido de la revolución en Francia, la expansión inglesa en el Mediterráneo se convertirá en un factor determinante en términos políticos, económicos y estratégicos, que se pondrá al servicio del sostenimiento de la causa antifrancesa ${ }^{11}$.

10. Sobre el comercio británico, M. N. García Fernández (2006) y M. ${ }^{a}$ del C. Lario de OÑATE (2000).

11. "The story of European international politics from 1763 to 1787 , as in other periods, refutes the notion that balancing practices and techniques promote equilibrium, limit conflict, and preserve the independence of essential actors, or can do so. Instead, they naturally tend to produce imbalance, hegemony, and systemic conflict. Only actual or aspiring hegemonic power can consistently practise balance of power techniques, and only fundamentalist can really believe the doctrine". P. W. Schroeder (1994), 48. Por otra parte, es interesante el estudio de Antonio Calvo Maturana sobre el conflicto de la isla de Nootka que puso en pie de guerra a España y Gran Bretaña en 1790. En el 
Sin duda, los acontecimientos de 1789 tuvieron una impronta crucial en el plano internacional. El estallido de la guerra supone para la potencia inglesa un nuevo periodo de galvanización en sus líneas de expansión. En el nuevo marco que se abre, al tenor de las recientes investigaciones de especialistas como Patrizia di Salvo y Diletta D'Andrea, ambas pertenecientes a la Universidad de Mesina, podemos conocer mejor las coordenadas de la estrategia que Gran Bretaña llevó a cabo en un espacio entendido vital para el mantenimiento de su propia posición, como potencia que pretende salvaguardar su comercio y su armada ${ }^{12}$.

La guerra frente a la República Francesa, el Consulado y el Imperio de Napoleón, muestran a una Gran Bretaña en el papel de principal valedora de las coaliciones antirrevolucionarias, combinando una actuación diplomática y armada contra Francia tanto en el frente continental como en el naval. Esta posición se adecúa a la búsqueda de equilibrio continental y contención que venía practicando Gran Bretaña, una estrategia para asegurar puertos y arsenales a la flota británica y así controlar las rutas comerciales. Gran Bretaña, adalid de ese equilibrio europeo, desarrolla en estos momentos una estrategia "defensiva" frente a la Francia revolucionaria. Relega el peso de la contienda a sus aliados en el continente: Austria, Prusia y Rusia; pero en el mar se ve obligada a tomar un rol activo. Es aquí donde interviene de forma directa, ofreciendo cobertura a los aliados, una posición activa de apoyo a cualquier agente que se atreva a luchar contra Francia. Ahora bien, con el pretexto de luchar frente a Napoleón, Gran Bretaña procederá a establecer el control directo de una serie de enclaves estratégicos por todo el Mediterráneo.

En este marco, uno de los elementos más relevantes e innovadores lo encontremos en el modo que tiene Gran Bretaña de ejercer ese dominio, mediante el desarrollo de un poder blando basado en el uso sistemático de la propaganda, de la difusión de gacetas, de la intervención en el mundo de las ideas y en la creación de una opinión pública, concebida como un instrumento que favorece la injerencia en los asuntos internos de los enclaves ocupados, para hacer valer en ellos los cambios políticos considerados necesarios para el establecimiento británico en la región ${ }^{13}$. Todo ello, Gran

artículo, mediante el tratamiento de las fuentes diplomáticas y consulares, se perciben las líneas de interés de Inglaterra en América y el Pacífico, dispuesta a disputar el teórico monopolio español desde el XVI. A. Calvo Maturana (2008).

12. P. Di Salvo (2013) y (2016). D. D'Andrea (2006).

13. P. Di Salvo (2013), 44-45. 
Bretaña lo realiza enarbolando el argumento principal de representarse a sí misma, no como invasora de los territorios que ocupaba, sino como el paliativo necesario frente a la invasión francesa ${ }^{14}$. Aquellos lugares protegidos y ocupados por Gran Bretaña en el Mediterráneo han sido definidos como "laboratorios de ingeniería constitucional", en los que los ingleses exportaban y experimentaban con formas de gobierno e instituciones, así como modelos de administración y de justicia, bajo la primera y necesaria afirmación de la libertad de imprenta, que favorecía la actuación en el campo de la información, generando una opinión dirigida a intervenir en los agentes sociales del territorio, en favor de la alianza inglesa y de las reformas ${ }^{15}$. Esta manera de intervenir fue puesta en práctica en todos los enclaves en los que Gran Bretaña puso su punto de mira, por ello los estudios de Patrizia di Salvo y Diletta D'Andrea nos muestran que el Mediterráneo fue concebido como un espacio estratégico de primer orden en la guerra europea.

A la presencia inglesa en Gibraltar y a los tratos comerciales que establecieron con el reino de Nápoles, se suma, al estallar la guerra contra la Convención, el apoyo explícito y conveniente de Gran Bretaña a los monárquicos corsos, que se rebelan contra París en 1794. La toma de Córcega por los británicos hace efectiva la promulgación de una Constitución y la separación de la isla de la República Francesa para unirse, como territorio autónomo, a la común soberanía de Jorge $\mathrm{III}^{16}$. Lo relevante de un acontecimiento como este es la ejemplaridad que resulta de una estrategia que será usada sistemáticamente contra Francia. Gran Bretaña ocupa posiciones en defensa de la independencia de los territorios frente al poder francés, y a su vez, promueve con su ocupación la implantación de un modelo político e institucional alternativo, que aunaba reformas y moderantismo frente a la radicalidad francesa. La presencia inglesa y la necesidad de reformas bajo su protección se defendía como el medio para impedir la llegada de los principios revolucionarios franceses junto a las tropas de Napoleón. Después de la toma de Córcega viene la de Malta, Cerdeña, Sicilia y las islas jónicas, en las que Gran Bretaña nos deja ver, a través de sus esfuerzos

14. D. D'Andrea (2006) hace referencia a la obra de G. F. Leckie, An Historical Survey, of the Foreign Affairs of Great Britain, with a view to explain the causes of the disasters of the late and present wars, London, 1808; en ella la estrategia británica en las coordenadas señaladas se hace palpable.

15. C. R. Ricotti (1998), 394.

16. P. Di Salvo (2013). 
propagandísticos, los enclaves estratégicos de interés para los ingleses en todo el Mediterráneo ${ }^{17}$.

El año 1806 supone un punto de inflexión en lo que respecta a la estrategia inglesa. Aislada frente a la progresiva claudicación de todas las potencias europeas, Gran Bretaña procede a establecer en Palermo y Mesina el centro de sus operaciones militares, para contrarrestar el bloqueo continental impuesto por Napoleón. La presión sobre Italia y la defensa de los borbones en Palermo representaría entonces una vía para desequilibrar al Imperio, golpeando precisamente en su periferia ${ }^{18}$. A raíz del exilio de los reyes de Nápoles a Sicilia, Gran Bretaña entendió la isla como la cabeza de puente para introducirse en la península, una tarea que resultó infructuosa durante todo el decennio francese ${ }^{19}$. Frente a la sistemática derrota de los poderes continentales, y ante el establecimiento de un poder hegemónico en manos de Napoleón, que destruye cualquier atisbo de equilibrio europeo, la situación en Europa desde 1806 hasta el inicio de la campaña rusa es la de un continente dividido en un marco bipolar, con la potencia naval británica a un lado y el poder territorial francés al otro.

A raíz del conflicto, el área mediterránea se convierte en un espacio vital en el que el poder británico tiene la necesidad de expandirse, y lo hará conformando una talasocracia que, desde Gibraltar y Menorca, pasando por Sicilia, Malta, Corfú, Creta y Chipre, llega hasta Alejandría, estableciendo una red de arsenales para proteger a sus aliados estratégicos, como Portugal, y resguardar su armada, asegurando el mercado y el tránsito de mercancías y de personas en Europa, África y Oriente. Con esa red de plazas y arsenales, en el plano estratégico procede a desestabilizar a un Imperio francés, que,

17. Ante la ocupación de dichos espacios nacen, como decimos, una serie de publicaciones que se unen a la Gazzetta Corsa, como el Giornale di Malta, el Foglio periodico di Sardegna, la Gazzetta Britannica de Messina y la Gazzetta Jonia entre otras. Idem.

18. "Sicily and Sardinia, together with Malta, the Ionian Islands and a few other territories, were at that time the only places within Mediterranean Europe not under French domination. As a consequence, Lord Grenville believed that their defence was essential: that Great Britain had to intervene was the shared opinion of the British Government and the bulk of public opinion [...] It was necesary to increase Britain's presence in order to find that counterweight to France sought in vain on the continent, and to extend the commerce on wich the British economic system was mostly founded". D. D' ANDREA (2006), 80-82.

19. Decennio francese es la expresión con la que se conoce la década del reinado de Joaquín Murat en Nápoles (1806-1816). Sobre el periodo, F. BARra (2008) y J. A. Davis (2014). 
sin flota desde Trafalgar en 1805, se veía obligado a proteger sus fronteras e imponer el bloqueo del comercio británico ${ }^{20}$.

El año 1808 abre otro horizonte. La guerra peninsular provoca un cambio en la estrategia de desgaste británica sobre el Imperio francés desde su periferia. El principal teatro de operaciones militares pasará de Italia a España. El tratado de alianza de la Junta Central con Gran Bretaña en 1809 supondrá el reconocimiento de la rebelión y el apoyo logístico, financiero y militar británico tanto a las instituciones como a la guerrilla, abriendo un nuevo campo de batalla de primer orden contra Napoleón ${ }^{21}$. Lo interesante en todo esto, ahora que conocemos el modo de proceder inglés con sus aliados, es reflexionar, adentrándonos en la especulación, sobre el grado de injerencia interna que Gran Bretaña pudo llevar a cabo en los asuntos españoles, pues como demuestra la política en Córcega, Malta o Corfú, los delegados de Jorge III procedían sistemáticamente a interferir en los asuntos internos de los aliados a los que protegían.

Durante el decennio francese, como consecuencia de la influencia inglesa y de la protección de la corte borbónica en Palermo, Gran Bretaña procedió de facto a intervenir en las decisiones del gobierno a través de su embajador. Con la mano derecha protegían a la familia real, con la izquierda intervenían en favor de los intereses de la nobleza siciliana. Los delegados británicos llegaron a intervenir de tal manera que lograron hacer de las Cortes tradicionales unas Cortes constituyentes que en 1812 aprobaron una Constitución a la inglesa. La corona, protegida por Gran Bretaña, llegó a encontrarse hasta tal punto anulada por el respaldo inglés a la nobleza siciliana que Fernando IV abdicó en su hijo Francisco, y este cedió ante las Cortes, que aprobaron la Constitución. Este era sin duda el concepto de equilibrio para Gran Bretaña: ejercer la tutela entre las partes mientras conseguía suculentos tratos comerciales que enriquecían su industria, industria que producía bienes que compraban sus protegidos. Gran Bretaña financió con capital la defensa de Sicilia, obtuvo capacidad para explotar sus minas de azufre y la pólvora, que de ese azufre se fabricaba, revertía en el armamento que vendía a Sicilia para su defensa ${ }^{22}$.

20. T. Benady (2016-2017). El especialista da cuenta de las redes de tráfico de individuos y mercancías entre las colonias británicas por el Mediterráneo con África, Asia y la metrópoli.

21. A. Laspra Rodríguez (2007).

22. "Ferdinando ebbe un ruolo marginale, mentro agli inglesi fu lasciato tutto il peso della guerra e questa situazione è sintomatica della posizione di protettorato britannico che la Sicilia aveva asunto e dello scarsissimo peso, soprattuto politico, del Borbone [...] 
Para España ha sido investigada la financiación británica de la rebelión, con partidas presupuestarias para la guerrilla y las Cortes, que debían introducir reformas liberalizadoras ${ }^{23}$. Entre los rebeldes españoles existía cierto grado de anglofilia y los postulados británicos estuvieron presentes en los debates constitucionales gaditanos ${ }^{24}$. A falta de mayor profundidad, es de sobra conocido el tradicional interés inglés por expandir su comercio a las colonias de Sudamérica. El apoyo a la causa española situaba a los ingleses en una posición ventajosa a la hora de llevar su comercio a las Indias españolas.

Sea como fuere, lo importante es que a partir de 1806/1808 Gran Bretaña se erige en protector de dos espacios que nos interesan: España y Sicilia. Y a través de su flota, las dos coronas volverán a establecer relaciones rotas diez años antes, y a reconciliarse para velar por intereses mutuos.

\section{DE LA DEPENDENCIA A LA TENSIÓN. LAS RELACIONES ENTRE ESPAÑA Y NÁPOLES DE 1759 A 1808}

"La storia settecentesca dei rapporti tra Napoli e Spagna è una storia di tensioni continue e crescenti dopo la partenza di Carlo di Borbone"25. La marcha de Carlos III hacia España en 1759 supone un acontecimiento clave para entender el desarrollo de las relaciones entre Madrid y Nápoles. El reino de Nápoles se constituye como un reino independiente en el

Si inserirono cosí i maneggi dell'ambasciatore inglese in Sicilia lord Guglielmo Cavendish Bentinck in appoggio della nobiltà che faceva parte dei circoli di opposizione al sovrano, per una strumentalizzazione volta ad indebolire sempre più la monarchia borbonica per dominare la situazione siciliana”. G. Coniglio (1999), 265-266.

23. A. Laspra Rodríguez (2007).

24. Referenciamos aquí una de las últimas investigaciones sobre el constitucionalismo español de 1812: J. Varela Suanzes-Carpegna (2013). En ella el autor reflexiona sobre las influencias de los modelos británico y francés en los debates políticos anteriores a la emanación de la Constitución de Cádiz, resaltando los contactos de algunos de los parlamentarios con el espacio, las ideas británicas y las tesis sobre la monarquía constitucional británica y su capacidad de implantación en una España cuyas cortes finalmente se decantan por el modelo francés de 1791. Aun así, los contactos del panorama liberal con la anglofilia son importantes y lo serían más en el futuro exilio. Destaca también, en relación con las tesis de Patrizia di Salvo, la presencia del periódico El Español, de Blanco-White, publicado en Londres durante toda la etapa de la guerra, un periódico, según el autor llamado a influir en los debates parlamentarios a favor de las tesis constitucionalistas inglesas. Para la influencia inglesa en el liberalismo español, M. Moreno Alonso (1983), 181-218.

25. A. M. RAo (2003), 601.

(C) Baetica. Estudios Historia Moderna y Contemporánea, 40, 2020, 195-231. Facultad de Filosofia y Letras, Universidad de Málaga. Departamento de Historia Moderna y Contemporánea 
Mezzogiorno a partir del reinado de Carlos en 1734. Aun siendo un reino independiente, permanece muy ligado a España en términos políticos y dinásticos. Esa dependencia comenzará a generar tensiones, a raíz de la marcha de Carlos a España en 1759. Fernando IV, como nuevo rey de Nápoles, protagonizará, junto a la reina María Carolina de Austria, el inicio de un proceso de distanciamiento que comienza a crear tensiones diplomáticas y políticas con España, pues el antiguo monarca, Carlos III, pretende tutelar su antiguo trono. Esta pretensión se traduce en la posición de fuerza que tiene Bernardo Tanucci en la corte napolitana, como agente de confianza del rey español, máximo exponente de la supervisión que Madrid pretende ejercer sobre los asuntos italianos. Esa reiterada pretensión de tutelaje supondrá en Nápoles la sucesión de enconadas muestras en favor de reafirmar la independencia del reino. Precisamente los intentos de tutela e intervención parecen generan la tensión y el distanciamiento que Madrid quería evitar, aunque, lógicamente la presencia austriaca e inglesa serán los factores principales que hagan mella en las relaciones políticas entre Nápoles y España durante las décadas siguientes.

Debemos entender las relaciones entre España y Nápoles dentro de las tensiones presentes en el equilibrio europeo. Como entidad independiente, Nápoles basculará poco a poco durante la segunda mitad del XVIII hacia la esfera austriaca y la esfera inglesa, en reacción a la presión dinástica de Francia y España sobre el eslabón más débil de la casa de Borbón. Teniendo presente esta dinámica, podemos diferenciar dos periodos en los que dividir las relaciones entre España y Nápoles, enlazando para ello elementos de política interna con las perspectivas en política exterior. Una primera etapa discurre desde 1759 hasta el estallido de la revolución en Francia, desde este momento, y a raíz de la Paz de Basilea, un segundo periodo discurre hasta la invasión de ambos espacios en 1806 y 1808. En estas dos etapas podemos discernir como ambas Cortes discurren en sus relaciones dentro de una tensión definida por sus posiciones de afinidad a una u otra de las potencias europeas, entrelazando las vicisitudes de la política interior con los intereses en el exterior, en relación con los poderes que comienzan a gravitar sobre el futuro de Europa como potencias militares, marítimas y económicas. El enfrentamiento secular entre Francia y Gran Bretaña tiene consecuencias en las posiciones estratégicas de Austria, España y Nápoles, descubriendo las contradicciones presentes entre la dinastía y los intereses de Estado, que llevarán al propio absolutismo napolitano a gravitar en las esferas de Austria y Gran Bretaña, a modo de freno de los intereses ajenos y de los poderes intermedios. La mayoría de edad de Fernando IV 
en 1768 y el final de la regencia napolitana serán el punto de partida de esa tendencia a la ruptura, que en 1776 provoca la caída de Tanucci, el confidente de Carlos en la corte de su hijo ${ }^{26}$.

\subsection{El influjo de Viena sobre el reino de Nápoles y la tensión con España}

La existencia del "Negociado de Italia" en la Secretaría de Estado y la posición de primer nivel que se da a los negocios italianos en la Instrucción reservada, son testimonios que dotan a la proyección italiana de la monarquía española de una impronta especial dentro de su diplomacia ${ }^{27}$. Tal proyección se concretaría guardando los intereses españoles y dinásticos en Parma y Nápoles, poniendo en valor la necesidad de tratos firmemente regalistas pero conciliadores con Roma y atendiendo al equilibrio y apoyo a la independencia de las repúblicas del norte, frente a la injerencia austriaca en la región $^{28}$. Las líneas políticas de la Secretaría de Estado se marcan a través

26. "La caduta di Tannuci, nel 1776, aveva segnato l'inizio di un più netto distacco dalla Spagna e di un pieno inserimento delle Sicilie nell' orbita austriaca, fermamente voluto e perseguito dalla regina Maria Carolina, non solo, anche da alcuni settori della nobiltà e degli ambienti intellecttuali che nel modelo asburgico di governo vedevano, gli uni, maggiori possibilità di potenziamento della propria influenza e dalla propria partecipazione agli orientamenti della corte e del governo, gli altri, una piu efficace politica riformatrice nei confronti della Chiesa e delle feudalità, quale vedevano practicata a Milano da Maria Teresa e in Toscana da Pietro Leopoldo". A. M. Rao (2003), 602.

27. R. Olaechea (1985), 7-101.

28. "Un interés general e indirecto respecto a la Italia entera puede ocupar en algún tiempo los cuidados de la España, si alguna potencia poderosa intentare invadir y subyugar los estados de los principados y repúblicas que ahora posee aquella hermosa porción de Europa. En tal caso, tanto el Papa como los reyes de las Dos Sicilias y Cerdeña, potentados de Toscana, Parma y Módena, repúblicas de Venecia, Génova, Luca y otras, merecerían la protección y auxilios de la España, combinada con otras cortes que pudiesen ayudar a los mismos". J. Moñino y Redondo, conde de Floridablanca (1982), 235-236. Los siguientes epígrafes resaltan el recelo a los intereses de otras potencias, principalmente el Imperio, y abogan por el cuidado de la independencia napolitana, así como de un trato con Roma pensando en la geopolítica, pero bajo el prisma de la defensa espiritual de la religión. Velar por la independencia de los pequeños estados del norte es un fundamento para el mantenimiento del status quo, además destaca la misma defensa para los cantones suizos "que franquean tropas y aún industria con los muchos individuos que se quedan en España y trabajan [...] sería bueno tener ministro permanente en Lucerna y Berna, por cuyo medio se podrían hacer las contratas con más conocimiento para el ejército, y atraer pobladores industriosos o establecerse en estos reinos". Ibidem, 239-240. 
de sus agentes y de su diplomacia. Las instrucciones y la correspondencia miden el pulso y muestran los intereses del Estado en sus representantes. Atendiendo a esto, parece que durante el reinado de Carlos III en España, la ambición de Madrid se mueve en torno a dos ideas analizadas por Rafael Olaechea y presentes en la relación epistolar de los embajadores con Madrid. Primero, intervenir de manera velada en el gobierno interno del Reino de Nápoles, y segundo, acoplar al mismo en su expresión exterior dentro del Pacto de Familia ${ }^{29}$, un pacto en el cual España también adolecía de inferioridad frente a Francia, un pacto que gozaría quizá de más equidad con dos cortes cercanas frente a una tercera más poderosa.

La segunda mitad del setecientos parece saldarse con el fracaso de estos términos. La mayoría de edad de Fernando IV señala el inicio del declive en la tutela española de Nápoles, un proceso que tradicionalmente se ha explicado adoptando como punto de fuga el matrimonio del rey Fernando con María Carolina de Austria, hija de la emperatriz María Teresa y Francisco de Lorena, un matrimonio que anticiparía por otra parte el de la hermana de María Carolina, María Antonieta, con Luis XVI de Francia ${ }^{30}$.

El periodo de estabilidad y paz asegurado por el Tratado de Aquisgrán dio a Italia un respiro que permitió a los estados italianos centrarse en sus preocupaciones por el gobierno interno y por la puesta en marcha de programas de reformas que siguieran el espíritu del siglo. La paz no acabó con las miras expansionistas de las diferentes potencias en la proyección de sus intereses estratégicos, comerciales y materiales, en una tierra de ricos puertos y recursos económicos, pero la política se dirimía por medio de la diplomacia. Las realidades internas están condicionadas por determinantes externos $^{31}$, y así, las bodas reales de Nápoles en 1767 son sin duda fruto de las alianzas dispuestas en el tablero europeo, que aproximaron a París y Viena frente a Prusia e Inglaterra. El mantenimiento de tales equilibrios

29. R. Olaechea (1985), 14.

30. L. BARRECA (1976).

31. "Fino all'inizio delle guerre revoluzionaire le loro aspirazioni egemoniche non su erano più concretate nell'agressione armata ma avevano piuttosto fatto ricorso, oltre che ái più tradizionali vincoli matrimoniali, alla formazione di sfere di influenza basate sull'opinione, sulle reti massoniche e culturali, oltre che alla creazione di rapporti commerciali di dipendenza e al rafforzamento di quelli qià preesistenti. Con l'insediamento in Toscana come granduca, nel 1765, di Pietro Leopoldo d'Asburgo e il matrimonio tra sua sorella Maria Carolina e il re di Napoli Ferdinando IV di Borbone, nel 1767, l'influenza austriaca in Italia si era ulteriormente rafforzata". A. M. RAo (2003), 588. 
en Europa supuso el detonante de las tensiones hispano-napolitanas ${ }^{32}$. En clave interna puede destacarse el aumento del influjo de Viena sobre la corte partenopea y los vínculos que la corte de Austria mantenía con el baronaggio feudal napolitano, inclinado a la independencia que gozó durante el periodo virreinal ${ }^{33}$.

La cercanía de Austria dotaría a los borbones napolitanos de un recurso para hacer valer su independencia frente a Francia y España, aunque su situación en el Pacto de Familia aseguraba una posición de fuerza frente a Prusia y las injerencias expansionistas del reino sabaudo sobre Milán, Parma y Piacenza. El elemento de mayor relevancia de la diplomacia napolitana fue el acercamiento a Austria, que preconizaba el matrimonio de Fernando IV y María Carolina, tratado antes de la partida de Carlos III para España y auspiciado bajo el propósito de unir las casas Borbón y Habsburgo en el marco del conflicto de los Siete Años ${ }^{34}$. Afianzar la paz y el equilibrio en Italia pasaba por buscar una relación entre Nápoles y Viena que no trastornase el influjo español. El apoyo a los borbones italianos por parte de la potencia austriaca en la península era asegurar, teóricamente, el poder de Felipe de Borbón en Parma y de Fernando de Borbón en Nápoles. Para Austria, estas relaciones familiares supondrían el mejor modo de penetración en Italia mediante una política matrimonial. Viena dio mayor importancia a la unión con el flanco débil de la dinastía borbónica en Italia que a la unión con las cortes de Madrid y París, lo que es representativo, sin duda, de los intereses del Austria y de su posición filo-borbónica como auténtica realidad coyuntural en el equilibrio de poder ${ }^{35}$.

María Carolina pronto será reconocida como una actriz principal en el reino de Nápoles, y a través de ella se entiende la relación entre los planes de reforma ilustrada en el interior del país con las posiciones cercanas a su

32. G. Coniglio (1999), 132-135.

33. Para estudios sobre la Corte napolitana, P. VÁzQuez Gestall (2008).

34. G. Coniglio (1999), 173.

35. "Carlo III vedeva assicurato ai descendenti di suo figlio il trono di Napoli e Sicilia, che veniva garantito dall'Austria e los stesso accadeva per il ramo di Filippo per il trono ducale di parma e Piacenza. L'Austria a sua volta si assicurava mediante una serie di matrimoni l'ingerenza a Napoli, Parma e Modena; governava direttamente il ducato di Milano e Mantova, indirettamente la Toscana. Veniva cosí a esercitare nell'Italia una forma di egemonia vantaggiosissima, che non costituiva un onere finanziario per elevate spese militari e non dava luogo a complicazioni di carattere diplomatico. La stessa Inghilterra, gelosa del predominio nel Mediterraneo, non vedeva una rivale in una potenza come l'Austria, che sul mare era particolarmente debole". G. Coniglio (1999), 177. 
Austria natal ${ }^{36}$. El plano exterior tenía sus ecos en el interior y la influencia austriaca estaba en la base del seguimiento en el sur de la estela del reformismo de Leopoldo en Toscana y José II en Lombardía. La reina de Nápoles, dentro del Consejo de Estado desde 1775, constituyó el principal acicate para provocar la caída de Bernardo Tanucci como secretario de Estado y disponer su sucesión por el marqués de Sambuca. Como elemento extraño a las directrices de Carlos III a su hijo Fernando, Carolina patrocinó dentro de la administración y de la corte a un individuo principal en su reinado: John Acton. Este fue un personaje cedido por el Gran Ducado de Toscana a la reina y llamado a implementar en Nápoles las reformas de la armada y del ejército, instrumentos de independencia, que habían dado muestras de debilidad en periodos anteriores ${ }^{37}$. Desde 1778 , este nuevo personaje sería nombrado secretario de Ejército y de Marina, y poco a poco, ascendería como favorito de los reyes en la corte napolitana, consolidando una relación de poder a tres que unía al secretario Acton con la reina Carolina y lord Hamilton, el influyente representante inglés en Nápoles ${ }^{38}$.

El objetivo fundamental era transformar el reino de Nápoles en un Estado moderno, dotarlo de la solvencia financiera necesaria para el sostenimiento de una fuerza naval y armada correspondiente a la posición que debía ejercerse en el Mediterráneo ${ }^{39}$. Esta tarea se lleva a cabo bajo la influencia de las reformas ilustradas puestas en práctica en las cortes de la casa de Habsburgo, el carácter de ese reformismo interno se suma en Nápoles al comienzo de un giro político hacia Viena ${ }^{40}$. La presencia austriaca en la

36. Para el estudio de María Carolina de Austria, C. ReCCA (2014a) y (2014b).

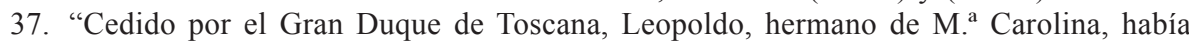
llegado a Nápoles el general Juan Acton, francés de nación [...] Vino a Nápoles en 1778, para hacerse cargo de la Marina; más tarde, nombrado ministro del Ejército y de la Marina [...] Con Acton la política napolitana dio un doble viraje; por un lado, fue buscando cada vez más ostensiblemente la protección austriaca, y por el otro, se hizo patente su amistad hacia Inglaterra, cuyo representante en Nápoles era lord Hamilton [...] El empeño de Carlos III y Floridablanca en destrozar al favorito Acton, factor fundamental de ese desviacionismo que sacaba a Nápoles de la órbita política de España, se hace comprensible. Acton era ministro de Guerra y de Marina, pero los negocios de los demás departamentos de gobierno pasaban por sus manos y los de la reina”. R. Olaechea (1985), 18-20.

38. R. Palumbo (1999). Para referencias sobre John Acton, G. Nuzzo (1980) y E. Pontieri (1932).

39. G. Coniglio (1999), 204.

40. Para adentrarse en el carácter del reformismo ilustrado napolitano, S. SCANDELLARI (2008) y C. CAPRA (2008). 
corte de Nápoles, lejos de apaciguar las tensiones y asentar los equilibrios, minaba las relaciones de una España empeñada en el tutelaje de su esfera de influencia mediterránea.

A estas dinámicas cabe sumar otro elemento importante, la incursión del comercio británico en la región ${ }^{41}$. En palabras de John Acton, las expediciones comerciales británicas que tocaban tierras sicilianas no suponían un peligro, muy al contrario, ceder ante esta pretensión era más bien un seguro que defendería constantemente las costas de un desembarco o de un ataque, y ofrecía al rey el beneficio de su defensa ${ }^{42}$. Tal es la razón del equilibrio desde la perspectiva napolitana, asegurar su independencia entre el lazo dinástico y los enemigos de las potencias borbónicas. Para la corte de Madrid tales derivas no eran por supuesto indiferentes, y contradecían la línea marcada de la política italiana, pasando del control de un equilibrio favorable a tener que enfrentarse de nuevo a las injerencias austriacas y británicas, que hacían bascular la independencia napolitana fuera de la esfera de influencia española. Tales tensiones se concretan en la crispación progresiva de las relaciones diplomáticas, que se suceden entre el protocolo y la intriga contra la reina napolitana y su favorito, sumando las reprimendas de Carlos III en la correspondencia a su hijo. Las instrucciones que Floridablanca elaboraba para sus embajadores en tierras vesubianas disponían un fin claro, lograr la destitución de Acton, entendiéndolo como principal agente de la deriva exterior, a la par ministro favorito en la corte. En las dos últimas décadas del XVIII se suceden infructuosas embajadas en las que se personifica el grado de tensión que imperaba entre ambas cortes, fruto de posiciones exteriores cada vez más disonantes ${ }^{43}$.

En 1786, tras la marcha del diplomático Campos, España quedará sin embajador oficial en Nápoles, manteniendo solo al cargo como único representante al cónsul Antonio Marqués. Las tensiones llevaron entonces a un vacío en las relaciones hasta la muerte de Carlos III en 1788, que

41. 'L'Inghilterra giungeva invece nel Mezzogiorno d'Italia por altre vie: attraverso i suoi bastimenti mercantili di alto tonnellaggio, e, particolarmente in Sicilia negli ultimi decenni del secolo, con la sua cultura empiristica, che fu insieme invito alla concretezza delle scienze fisiche e naturali”. G. Nuzzo, (1972), 366.

42. Giuseppe Nuzzo recoge las palabras de Acton: "Une expédition maritime quant'à l'Angleterre ne présentera jamais le danger essentiel qu'on a voulu présumer: on défendra constamment ses côtes d'un débarquement et attaque de quelque conséquence, et S.M.S. sera toujours montée au moins pour la défensive d'un tel côte". G. Nuzzo (1972), 367.

43. R. Olaechea (1985), 27-76. 
fue seguida de un periodo de distensión al comienzo del reinado de Carlos IV, sin duda, por el posicionamiento antirrevolucionario de ambos países frente a los sucesos franceses. Igual que años más tarde, se abre entonces un interregno de tácita situación en el mismo bloque al saltar por los aires el Pacto de Familia ante la proclamación de la República Francesa y el establecimiento de la Primera Coalición ${ }^{44}$.

\subsection{Godoy e Italia. De la Paz de Basilea a la invasión napoleónica}

La Paz de Basilea de 1795 y el gobierno de Godoy abren la siguiente etapa en las relaciones entre ambos reinos. A raíz de la Revolución Francesa, el frágil equilibrio y la contención, desgastado durante todo el xVIII, quiebra definitivamente. Para España la paz con la República y su posterior alianza es sin duda un hecho inaudito, moralmente deplorable para los que se escandalizaban del impío y usurpador terror francés, pero entendible dentro de la posición española. Ello no supuso un cambio geoestratégico para Madrid, que no dejará de lado su tradicional línea de proyección hacia la península italiana.

Las memorias de Godoy son testimonio de los intentos de afianzar las relaciones con el espacio italiano y de continuar con una política de intervención que se entendía en favor de un equilibrio favorable a la posición española. El equilibrio establecido en Aquisgrán, a pesar de los cambios producidos por la intromisión austriaca en las cortes borbónicas, estalla junto al equilibrio europeo a raíz de las victorias francesas frente a las coaliciones. París da al traste con la balanza italiana y crea en la península repúblicas vasallas de su poder y su propaganda. Para Anna María Rao, la política española ante este hecho, la política de Godoy para ser más exactos parece definirse sin describir un plan general, improvisando a la sombra de una sucesión de acontecimientos sin duda excepcionales ${ }^{45}$. Las dificultades en los tratos con Nápoles después de la Paz de Basilea atentan contra sus intentos de influir en la toma de decisiones, el gobierno de Godoy se encuentra entre la dependencia de la política francesa y el inmanente conflicto con Inglaterra a nivel continental y colonial ${ }^{46}$.

44. Ibidem, 81-86.

45. "Non sembra, infatti, di poter individuare una politica di ampio respiro, globalmente improntata a delle precise linee direttrici, ma piuttosto degli orientamenti che, a parte alcuni obiettivi costanti, mutano a seconda delle circostanze, dei momenti, dei condizionamenti politici interni e internazionali”. A. M. RAo (2003), 589.

46. Ibidem, 590 . 
El aislamiento de Napoleón en la campaña de Egipto, sumado a la intervención británica en Sicilia y la austro-rusa en el norte de Italia, obligaron a la retirada de las tropas francesas que sostenían los gobiernos de las repúblicas instituidas bajo su tutela. Presa de sus contradicciones y de su extrema dependencia exterior, los contingentes antirrevolucionarios restauraron el orden destituido en Nápoles y en Roma ${ }^{47}$. La Paz de Lunéville en 1801 dividía de nuevo Italia en una zona de influencia francesa al noroeste y una zona austriaca en el noreste, junto a los estados independientes de Roma y Nápoles ${ }^{48}$. Los intentos españoles de restablecer un equilibrio italiano favorable, junto al apoyo de la potencia francesa, no solo tenían en el agente austriaco un enemigo al que poner freno, sino que la principal injerencia ahora venía de la mano británica, de su presencia en el Mediterráneo, de su presencia en la corte de Acton.

La política de influencia que España pretendía seguir con respecto Nápoles sufre a raíz de la Paz de Basilea y el Tratado de San Ildefonso, pactos que Madrid establece con los regicidas, los asesinos de la hermana de María Carolina. Que Nápoles tratara la paz con Francia sin que España realizase su papel de interventor supuso otro golpe más frente a las pretensiones españolas. En 1797, precisamente por este hecho, Carlos IV decretó que la línea del correo conectaría directamente Madrid y Parma, dejando por tanto aislada a Nápoles. A pesar de todo, en los años previos a la invasión napoleónica, ambos reinos protagonizan un nuevo intento de acercamiento por medio de una alianza matrimonial, para tejer un consenso entre las dos ramas de la dinastía, representativo por otra parte del grado de distanciamiento al que se había llegado, que hacía necesario reafirmar los lazos dinásticos para apaciguar los ánimos. En 1802, después del primer exilio de la corte napolitana a Palermo, tienen lugar los matrimonios del futuro Fernando VII con María Antonia de Nápoles y de la infanta María Isabel con el futuro Francisco $\mathrm{I}^{49}$.

La proclamación imperial de Napoleón en 1804 coincide con el inicio de la formación del definido «partido fernandino» en España, en cuya raíz podemos situar a la propia María Antonia de Nápoles. El estado de guerra constante, las dificultades materiales interiores, el descalabro de Trafalgar y los problemas derivados del comercio americano, daban alas a una oposición

47. Sobre la República partenopea de 1799: C. Petraccone (1984) y (1989), M. Azzinnari (1999) y V. CuOco (1976). Sobre la primera restauración borbónica, L. Blanch (1945).

48. A. M. Rao (2003), 596.

49. Ibidem, 600-605. 
cortesana que enlazaba con la opinión pública, y como siempre, provocaba resonancias en el exterior. El mismo germen anglófilo napolitano echaba raíces en la corte española con el partido fernandino.

Antes del decennio francese la alianza de Nápoles con Gran Bretaña ya era firme y los puertos del Mezzogiorno habían servido de puente para la flota y el ejército británicos. Cuando la crisis interna del gobierno de Godoy y de la monarquía española en su conjunto se hace evidente después de Trafalgar, la imposición francesa del bloqueo continental decretado contra Gran Bretaña es violada por Fernando IV en 1806. Tras ello, la presencia de la flota británica y el desembarco de tropas inglesas en la península italiana otorgó al emperador el casus belli necesario para la invasión de Nápoles. La corte de Fernando huyó por segunda vez de Palermo. En febrero de 1806 es tomada Nápoles por los franceses y solo tres meses después, en mayo, la princesa María Antonia muere, pero el desvanecimiento de la influencia napolitana no cambiará ya el carácter abierto de la crisis española. Ambos sectores, Godoy y los fernandinos, buscan el apoyo napoleónico a su causa, la extensión del bloqueo francés a Portugal y el pretendido arbitraje francés de la crisis española provocaría el desenlace de Bayona ${ }^{50}$.

A partir de 1808, la rebelión de los españoles y la formación de instituciones de gobierno paralelas y enfrentadas a José Bonaparte necesariamente contribuiría a generar cambios en los ejes geopolíticos con respecto a las posiciones anteriores. La rebelión española sitúa a la Junta Central y a las Cortes de Cádiz en la esfera de influencia inglesa, compartiendo con Gran Bretaña la alianza que Londres mantendrá también con la corte siciliana $^{51}$. La presencia de cónsules sicilianos en Cádiz y en Gibraltar, como más adelante veremos, nos permite partir de la premisa de que existieron relaciones entre ambos espacios. La existencia de testimonios sobre comisiones diplomáticas extraordinarias reafirma una relación entre la rebelión española y la corte siciliana, ambos bajo el paraguas británico

50. E. La Parra López (2007), 255-267. Para más referencias al gobierno de Godoy y al fenómeno de las facciones políticas en las postrimerías de la invasión francesa: $\mathrm{P}$. Molas Ribalta (2003) y E. La Parra López (2010).

51. Biblioteca Nacional de España, R/60124(4): Tratado definitivo de paz, amistad, y alianza entre su majestad el rey de España y de las Indias don Fernando VII, y en su real nombre la Suprema Junta Central Gubernativa de los Reynos de España y de los de Indias, y su majestad el rey del Reyno Unido de la Gran Bretaña e Irlanda. Concluido y firmado en Londres en 14 de enero de 1809. Con su traducción al Castellano. De orden de su majestad, Imprenta de Hidalgo, Sevilla, 1809. 
en la contienda frente a Francia ${ }^{52}$. Investigaciones como las de Christiana Brennecke nos permiten especular hasta qué punto los intereses españoles y napolitanos vuelven a entrelazarse durante la contienda, pues en el Congreso de Viena el representante español será el principal valedor de la restauración borbónica en Nápoles y en los ducados de Parma, Piacenza y Gustalla, frente a Metternich y al Imperio Austriaco, que en ese momento defiende la legitimidad de Joaquín Murat como rey de Nápoles ${ }^{53}$.

\section{DE LA RUPTURAA LA RECONCILIACIÓN. COMUNICACIÓN Y DIPLOMACIA DURANTE LA GUERRA DE LA INDEPENDENCIA}

La crisis de 1806 y 1808 en Nápoles y España se salda con la invasión francesa de ambos territorios y la proclamación de nuevos monarcas en sus tronos. Aquellos que se levantaron en contra de los franceses quedaron adscritos a la alianza con Gran Bretaña para resistir frente al poder de Napoleón. Tanto Sicilia como la rebelión española se convirtieron en aliados y protegidos de Gran Bretaña en su lucha contra Francia. La guerra en el Mediterráneo constará desde 1808 de dos focos, la isla de Sicilia por una parte y España por la otra. El eco de la rebelión española llega en un primer momento hasta Austria, pero un conato de levantamiento popular es tempranamente sofocado ${ }^{54}$. Gran Bretaña, aislada ante la rendición del resto de potencias, emprenderá sola la guerra contra Francia en estos años y sostendrá a sus aliados con todo su esfuerzo. Pero en el interior de este esquema general operan otras realidades. La corona siciliana, si bien protegida por los británicos, sufre de una auténtica anulación en el ejercicio de su soberanía real frente al poder de decisión inglés ${ }^{55}$. Las juntas provinciales y la Junta Central en España emprenden in extremis la tarea de acoger en sus manos la soberanía del rey secuestrado, para gobernar una rebelión ante una invasión externa y un terrible aislamiento internacional.

52. AHN, Estado, leg. 21, doc. 153: Relación del diario que con las cartas y notas de oficio han presentado a la Superior Junta de Observación y Defensa de este Reyno sus comisionados a Cerdeña y Sicilia, don Joseph Febrer y de Pedro, y don Antonio Mordella y Spotorno. Valencia: Por Joseph Estévan y hermanos, 1809. Estado, leg. 48, doc. 94: Informe de José Julián, teniente de navío, sobre el traslado de los comisionados a Cerdeña y Sicilia. Alicante, a 26 de abril de 1809.

53. C. BRENNECKe (2010).

54. S. Torre Fernández del Pozo (2007).

55. G. Coniglio (1999), 261-269. Para conocer al embajador inglés de este periodo, F. Renda (2011). 
Reflejo de estas circunstancias críticas, la situación de los agentes diplomáticos españoles en el exterior es cuanto menos inestable. Algunos juran fidelidad al rey José, otros huyen de sus respectivos puestos ante la situación. Privados de noticias, aislados, sin dinero y frente a la disyuntiva de instituciones paralelas, la capacidad de decisión es cuanto menos difí$\mathrm{cil}^{56}$. La política europea se encuentra bipolarizada por ingleses y franceses, la diplomacia tiene como centro París y Londres, y a esta última capital acuden los representantes de las juntas provinciales de Asturias, Galicia y Sevilla en busca de apoyo y reconocimiento. En enero de 1809 queda fijado el tratado de alianza con Gran Bretaña y junto a las misiones diplomáticas extraordinarias, que parten hacia Londres, Lisboa, Viena o Constantinopla para conseguir apoyo económico y militar, en febrero de 1809, dos comisionados de la Junta de Valencia, investidos por la Junta Central, parten con el mismo propósito a Palermo.

La corte de Sicilia y la rebelión española se encuentran en el mismo bloque, compartiendo la misma lucha por su supervivencia. Ante las nuevas circunstancias, el establecimiento de relaciones cordiales entre ambos espacios es un hecho. La rebelión busca apoyo material y simbólico: armas, víveres y reconocimiento; la corte siciliana, por otra parte, encuentra en los rebeldes españoles a los defensores de la legitimidad de la dinastía borbónica al trono. En este contexto se producen tres acontecimientos que nos permiten hablar de la existencia de relaciones cordiales y permanentes durante el periodo.

\subsection{El viaje de Leopoldo de Borbón a Gibraltar}

El primero de los acontecimientos que demuestran las relaciones entre España y Sicilia nos muestra también un nexo entre la rebelión española y el exilio siciliano en la defensa conjunta de la legitimidad dinástica de la casa de Borbón. Fruto de este principio rector en la lucha contra Francia, tiene lugar la misión diplomática que Fernando IV encargó a su hijo Leopoldo de Borbón, príncipe de Salerno, que puso en marcha una legación que partió desde Sicilia rumbo a Gibraltar el 27 de julio de 1808. La doctora Nava Rodríguez refiere la naturaleza de este viaje. Leopoldo viaja a España en un intento de hacer valer los derechos dinásticos de Fernando IV al trono de España. Ante la anómala situación que se vive en el país, descabezado de su soberano, Leopoldo reclama el reconocimiento de Fernando IV como regente en nombre de Fernando VII, secuestrado por Napoleón. En "Políti-

56. M. Á. Ochoa Brun (1996). 
ca, diplomacia y movilidad en la Europa napoleónica. El viaje a España de Leopoldo de Borbón, príncipe de las Dos Sicilias", la doctora Nava Rodríguez nos pone al tanto de la biografía de Leopoldo, como hijo segundón de la rama napolitana de la dinastía, y referencia las fuentes de archivo donde se recogen los testimonios de esta misión ${ }^{57}$. A todas luces, la maniobra está inserta en los intentos de Fernando IV por reclamar el trono de España y el favor de los rebeldes españoles, ligando las luchas emprendidas a ambos lados del Mediterráneo occidental y dotando de unidad a una causa común. Aunar en la persona del exiliado rey napolitano las causas de Italia y España podría dotar de mayor gravedad a la figura de Fernando y coordinar en torno a su soberanía las operaciones en ambos espacios.

La empresa fracasó y en noviembre de 1808 Leopoldo volvió a su patria con las manos vacías, al tiempo que las instituciones rebeldes asumían la soberanía nacional, que, ante la ausencia del rey, recaía de forma circunstancial en los cuerpos del reino. Tampoco debemos olvidar la realidad que se impone en ambos espacios, tanto el exilio siciliano como la rebelión española son sostenidas por Gran Bretaña, y precisamente el gobierno británico hospedaría la empresa de Leopoldo en Gibraltar. La pregunta sería por qué no se le permitió salir a territorio español. Esta decisión es polémica, sin duda, y se ofrece a cierto grado de conjetura ante la falta de cotejo en las fuentes. ¿Acaso Gran Bretaña prefería mantener a sus aliados bajo su protección, pero separados entre sí? Como decimos, esto es pura especulación, pero no obstante el aparente fracaso de Fernando IV en su intento de ser reconocido legítimo rey de España, la relación entre ambos espacios no hace más que comenzar $^{58}$. En febrero de 1809, dos comisionados de la Junta de Valencia, investidos por la Junta Central, parten a Palermo en misión diplomática.

\subsection{La comisión extraordinaria de la Junta a Sicilia}

La Relación del Diario que con las cartas y notas de oficio han presentado á la Superior Junta de Observación y Defensa de este Reyno sus comisionados á Cerdeña y Sicilia, D. Joseph Febrer y de Pedro, y D.

57. M. T. Nava Rodríguez (2017).

58. "La misión del Príncipe Leopoldo vertebra un contexto sumamente atractivo desde los intereses de la importancia de la historia comparada y subraya el protagonismo de los individuos que actuaron como agentes político-diplomáticos de los Borbones españoles y napolitanos entre 1808 y 1814 , durante el trascendental periodo en el que convivirían la Guerra de la Independencia y el «Decennio francese» napolitano". Ibidem, 214. 
Antonio Mordella y Spotorno ${ }^{59}$, es una relación de sucesos impresa publicada en Valencia en 1809. Por su formato nos informa sobre el fin propagandístico del documento. En él se pueden leer los objetivos de la comisión, el carácter de las relaciones y la presencia del importante papel que juega la red británica en estos contactos a través del Mediterráneo.

De los miembros de esta comisión sabemos poco, de Antonio Mordella podemos intuir por varias fuentes que reside en Cartagena, aunque en una carta que se eleva a la Junta Central, con peticiones de recompensa por la tarea realizada en Sicilia, se hace referencia a una procedencia genovesa ${ }^{60}$. Su posición social quizá se encuentre dentro de una incipiente burguesía comercial con intereses en Italia, al modo de aquella que expone Victoria López-Cordón en sus estudios ${ }^{61}$. Sobre Joseph Febrer y de Pedro tampoco sabemos mucho. Rastreando su nombre encontramos referencias a su cargo, junto a su hermano Joaquín Febrer y de Pedro, como alférez de fragata en 1799, ascendidos a alférez de navío en 1802. Ambos hermanos parecen ser naturales de Cartagena ${ }^{62}$.

Mordella y Febrer parten de Cartagena como representantes de la Junta Central en la corbeta Sebastiana del capitán José Julián rumbo a Sicilia el 5 de febrero de 1809, portan consigo un gran volumen de documentos y gacetas para informar sobre el estado de la rebelión. El 14 de febrero desembarcan en Cagliari a causa del mal tiempo. En la relación de sucesos no se pone demasiado énfasis a este hecho, pero el informe del capitán Julián nos muestra que esta parada no estaba prevista en el itinerario de la comisión ${ }^{63}$. Aun así, Mordella y Febrer tienen audiencia con la familia real y la legación inglesa en Cerdeña. En esa audiencia se procede al traspaso de información y a la obtención de permisos para comerciar con el gobierno sardo. El 16 de febrero la comisión abandona Cerdeña y llega a Palermo el 19, dos días después del proclamado entusiasmo popular ante la llegada de españoles, la comisión tiene audiencia con la familia real siciliana. Las muestras de afecto y hermandad toman un carácter prioritario en el impreso. Se suceden las audiencias con los reyes y príncipes, con el secretario de Estado, marqués de Circello, y con los representantes ingleses en la isla. Se procede entre ellos al traspaso de infor-

59. AHN, Estado, leg. 21, doc. 153.

60. Ibidem, doc. 156. Carta a la Junta Suprema Central elevando las peticiones de Antonio Mordella por el éxito de su comisión a Cerdeña y Sicilia.

61. M. ${ }^{a}$ V. López-CORdón CORTEZo (1986).

62. Estado general de la armada. Año de 1799. De orden superior, En la imprenta real, Madrid, 1799; y Gazeta de Madrid, viernes 15 de octubre de 1802.

63. AHN, Estado, leg. 48, doc. 94. Informe de José Julián, teniente de navío, sobre el traslado de los comisionados a Cerdeña y Sicilia. 
mación, se relata la elaboración de pasquines para ser difundidos en Italia, como propaganda para desmentir el relato francés sobre la rebelión española. La comisión obtiene del gobierno de Palermo armas, víveres y un cargamento de joyas pertenecientes a María Antonia de Nápoles, princesa de Asturias y primera esposa de Fernando VII, fallecida en 1806. Estas joyas son entregadas a la comisión con el propósito de destinarse a la caridad, para financiar gastos en veteranos, heridos o familias de soldados fallecidos.

Mes y medio después, el 31 de marzo, la comisión parte de regreso desde Palermo y llega a Palma de Mallorca el 11 de abril. Desde allí recala en Menorca para recoger otro cargamento de armas, que, a través de las órdenes del representante inglés en Sicilia, fue trasladado desde Malta a Mahón, para ser recogido por la comisión. Con armas, víveres, joyas, documentos y el apoyo diplomático siciliano, la comisión finalmente regresa a Alicante el 25 de abril, según fecha el propio José Julián en su informe del 26 para la Junta Central.

Reseñado el itinerario de Mordella y Febrer, los objetivos que se desprenden de la comisión son varios. Primero, la circulación de información y la transmisión y difusión de propaganda, reiterada varias veces cuando se hace referencia a las gacetas y papeles con que se cargan los comisionados. Segundo, el reconocimiento por parte de las cortes a las que se llega, en este caso buscando difundir un clima de hermandad entre los rebeldes españoles y Palermo, apelando a la unidad de la casa de Borbón. Tercero, conseguir apoyo económico y armamentístico, que es el fruto material de la comisión y en el que un factor importante, la red de agentes ingleses en el Mediterráneo, contribuye a favorecer como intermediario.

Los documentos, por tanto, indican la presencia de una relación bilateral, extraordinaria en principio, pero amigable y de colaboración entre la Junta y Palermo. Los objetivos de la misma, derivados de las acuciantes necesidades de la situación, dejan ver no obstante un clima de solidaridad mutua y unos intereses compartidos. La importancia de los agentes británicos queda patente como elementos que articulan en torno a sí las relaciones. Por último, estos documentos ofrecen datos sobre la red de personalidades a tener en cuenta en estos contactos.

\subsection{Un canal de comunicación permanente. El consulado de Emmanuelle Viale}

Más allá del viaje de Leopoldo en 1808 y de la comisión de Mordella y Febrer en 1809, como ejemplo de relaciones permanentes entre ambos espacios, el consulado de Maquiavelli y Viale viene a reforzar los contactos 
entre España y Sicilia. La documentación generada por ambos cónsules en su misión a España se encuentra custodiada en el Archivio di Stato di Napoli (ANS). Del grueso de la documentación, aquella de Emmanuelle Viale nos permite identificar al cónsul de Gibraltar como un enlace permanente en una relación a tres entre España, Gran Bretaña y Sicilia, reflejando la existencia de una red de contactos y un flujo de información y dinero que navega por el Mediterráneo a través de los correos y las flotas inglesas que conectan Palermo y Gibraltar.

La colonia británica en el estrecho se rebela como una pieza estratégica clave, puerta de entrada al Mediterráneo, y por ello el cónsul siciliano adquiere un carácter altamente relevante. La presencia de Viale en Gibraltar dota a las relaciones entre Sicilia y España de un carácter constante durante la guerra. Entre las funciones de los cónsules, más allá de su naturaleza como agentes de carácter comercial, se encuentran tareas administrativas, notariales e informativas ${ }^{64}$. Ante la situación crítica y ajena a la normalidad diplomática en tiempos de guerra e invasión, las funciones del cónsul ven potenciado su lado político en tareas como la recopilación de información o el espionaje. La documentación de Viale es testimonio de su implicación en la búsqueda de información para ser puesta a disposición de la corte, dando cuenta de acontecimientos políticos y militares que suceden a su alrededor. No obstante, su propia correspondencia parece revelar al cónsul no como un espía al uso, sino como un enlace, alguien encargado de recopilar información de otros agentes dispersos en el territorio, pero interconectados con él, a la cabeza de una red de individuos y un flujo de información y dinero.

El legajo 2651, Affari Esteri, del ASN, contempla la relación epistolar entre el cónsul de Gibraltar y la secretaría de Asuntos Exteriores en Palermo, podemos ordenar sus documentos del siguiente modo: 1) Correspondencia testimonial; 2) Informes sobre acontecimientos políticos y militares;

64. Antes de presentar y reflexionar sobre el contenido de los documentos del Consulado de Gibraltar entre 1808 y 1814 es pertinente considerar brevemente la naturaleza de la institución del consulado y el tipo de documentación que por su función genera. Para ello contamos con la obra de un especialista como Jesús Pradells Nadal, que se antoja sin duda obligatoria. Pradells atribuye como principal función de los cónsules ser agentes de naturaleza protectora para sus connacionales en un país extranjero. No obstante, junto a esta definición, el especialista refiere el carácter problemático que de manera permanente sufre la institución del consulado en cuanto a la estricta estipulación de sus competencias, que en consecuencia pueden parecer en exceso vagas o indeterminadas. Destacamos sus diferentes estudios: J. Pradells Nadal (1992), (1990) y (1996). 
3) Cuentas y extractos bancarios; 4) Impresos y gacetas. Analizando los documentos, el contenido de los mismos refleja aspectos muy sugestivos para hablar de las relaciones y las preocupaciones del cónsul. Nos hemos centrado en aquellos nombres propios que permiten discernir una red de contactos, en las emisiones de dinero realizadas y en las referencias a acontecimientos que el cónsul resalta en los informes que manda a Sicilia.

Los documentos custodiados en el ASN nos muestran a un individuo entendido como enlace, un agente siciliano dentro de la esfera británica y en territorio hispánico, un enlace de la corte de Palermo con otros individuos dispersos por el mapa español con los que se establece una interacción. Los documentos nos muestran la presencia de agentes sicilianos en la península, agentes que actúan en el territorio español durante la guerra y que, de un modo u otro, tienen una vía de comunicación con el centro de decisiones siciliano a través del cónsul gibraltareño. Este sería el caso de nombres propios como Marco Maquiavelli, del cual podemos saber su posición como cónsul siciliano en Cádiz, pero también de otros individuos recurrentemente citados en los papeles de Viale, de los que tristemente sabemos poco o nada, como sería el caso de Francesco Martorana, Osvaldo Gorgoni, Vincenzo Tripaldi o Gherardo Robertone ${ }^{65}$.

Del titular del consulado también sabemos poco, quizá el perfil de Emmanuelle Viale se asemeje al que describen estudios sobre el carácter socioeconómico de los cónsules ${ }^{66}$. Su posición conllevaría, en teoría, un

65. El caso de Robertone es sin duda relevante, porque de manera ininterrumpida focaliza el interés de Palermo en las comunicaciones con Viale de los primeros meses de 1809. ASN, Affari Esteri, leg. 2651. Carta de Circello a Gibraltar donde se solicitan noticias del caballero Robertone. Palermo, 17 de abril de 1809. Affari Esteri, leg. 2651. Carta de Circello a Gibraltar donde se solicita a Viale que se encargue de tener noticias de Robertone. Palermo, 8 de mayo de 1809. Affari Esteri, leg. 2651. Carta de Marco Maquiavelli a Emmanuelle Viale donde el cónsul de Cádiz comunica a Gibraltar que Robertone salió de Aranjuez y se oculta en Madrid. Cádiz, 6 de febrero de 1809. Robertone es definido como ministro en algunas cartas, es posible que fuera embajador, y todo apunta a que se encuentra al lado de la Junta Suprema tanto en Aranjuez como tras su huida a Sevilla.

66. "En términos generales puede afirmarse que, por su extracción social, y por las características de su oficio, los modos de su vida cotidiana son, en general, asimilables a los de las oligarquías urbanas de los territorios en que les tocó servir. Nobleza no titulada, burguesía mercantil y funcionarios altos y medios de la Administración civil y militar, que ejercerían el control de la vida económica, social y política de sus municipios, forman un estrato intermedio entre los arquetipos tradicionales de las formas de la vida aristocrática y el difuso concepto de lo popular". J. Pradells Nadal (1991), 210. 
trabajo dirigido a asuntos económicos y comerciales, aquellos que definirían el consulado, pero debido al momento crítico no parece ser el centro de su cometido. Efectivamente, Emmanuelle Viale parece más preocupado por controlar los flujos de pliegos que desde una y otra parte le remiten, como si ejerciera de agente intermediario en la gestión del recibo y envío de comunicaciones que deben ser expedidas a otros destinatarios. Esta faceta hace que conozcamos el canal de información, pero no aporta más $\mathrm{y}$, por tanto, desconozcamos el contenido específico de muchas de aquellas comunicaciones de las que Viale hace acuse de recibo.

La fecha de inicio de sus comunicaciones data de 1809, pero las cuentas que presenta y que más adelante veremos lo sitúan en Gibraltar quizá en diciembre de 1808. La comunicación del cónsul con el secretario de Asuntos Exteriores, Tommaso di Somma, marqués de Circello, comienza en febrero de 1809 , pero el reconocimiento oficial por parte británica de Viale como cónsul se realiza en la primavera del mismo año ${ }^{67}$.

Uno de los elementos más interesantes que la documentación permite atestiguar el instrumento mediante el cual Viale articula dichas comunicaciones. Nuestro cónsul parece definirse ante todo como un emisor y un receptor de información a ambos lados de su posición, privilegiado por el lugar en que se encuentra. A nivel peninsular, vemos que la correspondencia que mantiene con diversos individuos se realiza por medio de canales ordinarios de correo que comunican Gibraltar con Cádiz, Málaga, Granada, Sevilla o Madrid. Pero lo interesante a este respecto es la comunicación por mar, es decir, aquella que se remite a Sicilia, porque se realiza la mayoría de las veces por medio de las flotas inglesas que al tiempo que mueven la armada de guerra, traen y llevan consigo el correo ${ }^{68}$.

Del grueso de documentación generada por el cónsul, Viale remite a la corte una serie de informes de cuentas y extractos bancarios que contienen información muy persuasiva a la hora de referenciar la existencia de un flujo de dinero gastado por el cónsul en sus tareas cotidianas, en el envío

67. ASN, Affari Esteri, leg. 2651. Carta a Gibraltar del príncipe de Castelcicala donde comunica a Viale su nombramiento oficial como cónsul para los asuntos de comercio en el peñón. Londres, 21 de marzo de 1809. Affari Esteri, leg. 2651. Carta a Palermo del príncipe de Castelcicala donde comunica a Circello la aprobación de Jorge III de Viale como cónsul siciliano. Londres, 19 de junio de 1809.

68. ASN, Affari Esteri, leg. 2651. Carta de Viale a Palermo donde informa de la llegada del navío de guerra británico que partirá para Malta y de la llegada de una comunicación del caballero Robertone, en la que agradece a Circello de haber escapado de los franceses. Gibraltar, 14 de marzo de 1809. 
de correos o en el pago a diversos individuos. Un informe de cuentas que refleja movimientos desde 1808 a 1811 nos permite conocer gastos en suministros y partidas destinadas a Maquiavelli, Robertone, Gorgoni o Tripaldio. Estos dos últimos personajes parecen ser oficiales al servicio de su majestad siciliana en colaboración con los ejércitos anglo-españoles ${ }^{69}$.

A este informe de gastos se añaden comunicaciones que profundizan en los pagos realizados para la adquisición de impresos y gacetas que serían posteriormente enviados a Palermo. Carlo Bouisson es el nombre del librero al que compra la prensa local y regional, cuyos ejemplares se conservan en el legajo, si bien una pequeña muestra de mediados de $1814^{70}$.

Tres extractos bancarios de 1809, 1810 y 1811 respectivamente, ofrecen un desglose esquemático de los gastos expedidos en diversos conceptos. La cuenta bancaria que gestiona el cónsul gibraltareño está a nombre del secretario de Estado, Circello, y sus movimientos reflejan gastos en correos a Maquiavelli o a Martín de Garay, secretario de Estado de la Junta Central $^{71}$. La red de contactos e informadores se acrecienta en estos papeles con Luciano Sparatore, Antonio Precarico o Ferdinando Brazello, individuos que se encuentran en suelo español. En los extractos se referencia sistemáticamente el envío de correos a Cádiz, Lisboa, Palermo, Malta e Inglaterra, a la par que nos informa de la expedición de pasaportes y documentos para los vasallos de su majestad siciliana que se encuentran en España, bajo la protección del cónsul Viale ${ }^{72}$.

69. ASN, Affari Esteri, leg. 2651. Aprobación de los gastos hechos por Viale desde diciembre de 1808 a julio de 1811. Palermo, 31 de agosto de 1811. En su interior la comunicación conserva el informe realizado por el consulado de Gibraltar.

70. ASN, Affari Esteri, leg. 2651. Carta de Viale comunicando a Circello los pagos a Carlo Bouisson por la adquisición de gacetas. Gibraltar, 8 de abril de 1809. Affari Esteri, leg. 2651. Carta de Viale a Circello donde comunica el pago realizado a Carlo Bouisson por la adquisición de prensa. Gibraltar, 8 de abril de 1811. En el legajo se conserva una muestra de la prensa que Viale obtiene por medio del librero Bouisson. Las conservadas datan de 1814 pero sirven como ejemplo representativo de aquellas que adquiriría: Mercurio gaditano, Diario patriótico de Sevilla, Gaceta de Madrid, Atalaya de la Mancha, Gaceta de la Regencia de las Españas y Gibraltar Chronicle.

71. ASN, Affari Esteri, leg. 2651. Carta de Viale donde comunica a Circello el recibo de pliegos del secretario para Martín de Garay y para el general Joseph Caro. Gibraltar, 9 de abril de 1809. Affari Esteri, leg. 2651. Carta de Circello donde comunica a Viale la aprobación del gasto realizado por el cónsul para el envío del correo expreso a Cádiz con las cartas para Martín de Garay. Palermo, 13 de mayo de 1809.

72. ASN, Affari Esteri, leg. 2651. Carta de Viale a Circello en la que remite el extracto de la cuenta corriente con los gastos realizados en el año 1809. Gibraltar, 30 de diciembre de 1809. Affari Esteri, leg. 2651. Carta de Viale a Circello en la que remite el extracto 
Aparte de las cuentas, el cónsul remite a la corte informes donde detalla acontecimientos relevantes en su posición, algunos de los cuales están relacionados directamente con la función del cónsul como intermediario en el envío de comunicaciones. En 1811 informa, por ejemplo, sobre la epidemia de gripe amarilla que asola el litoral levantino y que interfiere en el funcionamiento ordinario de correos y comunicaciones. Informa también sobre polémicas surgidas ante la difusión de propaganda antibritánica en la zona $^{73}$. Durante 1813 y 1814 , las comunicaciones del cónsul informan a Palermo de las últimas campañas de la guerra, y se adentran en el clima español previo a la restauración fernandina, dotando a sus despachos de una información digna de reseñar, si tenemos en cuenta que la monarquía siciliana también se encuentra deseosa de librarse de su Constitución y reconquistar los territorios continentales gobernados por Murat.

Viale informa sobre los debates gaditanos, sobre los avances de Wellington y Castaños, sobre la llegada de noticias de las derrotas francesas en Rusia, sobre las tropas sicilianas que desembarcan en Alicante para apoyar la causa fernandina ${ }^{74}$. Refleja las buenas relaciones con el gobierno inglés de la colonia, recalca el gran esfuerzo y trabajo que realiza en su puesto al servicio de su majestad, y en 1814, se encarga de informar que el nuevo rey de Francia, ante la derrota de Napoleón, no aceptará Constitución alguna ${ }^{75}$. Estas noticias, sin duda, alentarían a la corte siciliana, al tiempo que Viale comunica la rebelión que tenía lugar en Málaga, Granada o Sevilla frente a los cargos institucionales y las Cortes de Cádiz ante la llegada de Fernando VII a España. Una copia del Real Decreto de 4 de mayo de 1814, por el cual Fernando VII desde Valencia deroga la Constitución de 1812 y declara nula toda la obra de las Cortes de Cádiz, es enviada a Palermo ${ }^{76}$.

de la cuenta corriente con los gastos realizados en el año 1810. Gibraltar, 28 de noviembre de 1810. Affari Esteri, leg. 2651. Carta de Viale a Circello en la que remite el extracto de la cuenta corriente con los gastos realizados en el año 1811. Gibraltar, 1 de agosto de 1811.

73. ASN, Affari Esteri, leg. 2651. Carta de Viale a Circello. Gibraltar, 14 de agosto de 1811.

74. Ibidem. Carta de Viale al príncipe de Belmonte. Gibraltar, 17 de agosto de 1813.

75. Ibidem. Carta de Viale al príncipe de Villafranca. Gibraltar, 27 de mayo de 1814. En una postdata de ese informe el cónsul escribe: "Si è saputo che il re di Francia non accetta la Constituzione".

76. Viale informa además sobre las persecuciones que comienzan a sufrir en España liberales como Agustín Argüelles, Bartolomé Gallardo o José María Queipo de Llano, conde de Toreno, futuro autor de la famosa obra sobre la revolución española. ASN, Affari Esteri, leg. 2651. Carta de Viale al príncipe de Villafranca en la que comunica que Bartolomé Gallardo "é stato arrestato a otto legue di Madrid ed il conte di Toreno 
A modo de conclusión, podemos discernir en estas comunicaciones la existencia de intereses compartidos entre España y Sicilia en su lucha contra Francia, pero también interpretar las expectativas que albergaba la corte de Palermo en el desarrollo de los sucesos españoles, a fin de encontrar aliento y ejemplo para la causa de la legitimidad dinástica y la restauración absolutista.

Durante los años de la guerra existe un flujo de información y dinero que circula entre Palermo y España, y en el interior del país se encuentran diversas personalidades en contacto con las operaciones militares y la vida política de la rebelión. A falta de mayor profundidad, estos testimonios de la comunicación entre el exilio siciliano y los rebeldes españoles nos muestran el renacer de las relaciones entre ambos territorios. El papel de la representación española en el Congreso de Viena, como principal defensora de la restauración borbónica de Nápoles frente a las reticencias de Austria y Gran Bretaña, podría constituir un cuarto acontecimiento que, sumado al resto, nos permitiría hablar de una reconciliación entre los borbones de España y los borbones de Nápoles.

\section{BIBLIOGRAFÍA}

Álvarez-Ossorio Alvariño, Antonio (2004), "Felipe V en Italia: El Estado de Milán bajo la casa de Borbón", en E. Serrano Martín (coord.), Congreso internacional Felipe V y su tiempo, Institución Fernando el Católico, Zaragoza, pp. 775-852.

Azzinnari, Marina (1999), La Repubblica Napoletana del Novantanove. Memoria e mito, Archivio di Stato di Napoli, Gaetano Macchiaroli editore, Napoli.

Barra, Francesco (2008), Il decennio francese nel Regno di Napoli (1806-1815). Studi e ricerche, Plectica, Salerno.

Barreca, Luigi (1976), Il tramonto di B. Tanucci nella corrispondenza con Carlo III di Spagna (1777-1783), Palermo.

Benady, Tito (2016-2017), "Inmigración en Gibraltar procedente de las otras colonias británicas del Mediterráneo: Menorca en el siglo XVIII, y Malta en el siglo XIX", Cuadernos de Gibraltar, 2, pp. 329-338.

Blanch, Luigi (1945), "Il regno di Napoli dal 1801 al 1806", en B. Croce (a cura di), Scritti storici, tomo 1, Laterza, Bari, pp. 3-292.

andando alla sua provincia, gli arresti continuano e vari arrestati caminano per dislenti essili in Extremadura". Gibraltar, 1 de junio de 1814. Affari Esteri, leg. 2651. Carta de Viale al príncipe de Villafranca en la que comunica la causa abierta a Agustín Argüelles. Gibraltar, 6 de agosto de 1814. 
Brennecke, Christiana (2010), ¿De ejemplo a 'mancha' de Europa? La Guerra de Independencia española y sus efectos sobre la imagen oficial de España durante el Congreso de Viena (1814-1816), CSIC y Doce Calles, Madrid.

Calvo Maturana, Antonio (2008), “Génesis del II Imperio Británico y ocaso del universalismo español: La doble vertiente del conflicto de Nootka (1790)", Hispania, LXVIII, 228, pp. 151-192.

CAPra, Carlo (2008), "El final del Antiguo Régimen en Italia (1780-1820)", Cuadernos de Historia Moderna, Anejos, VII, pp. 115-134.

Coniglio, Giuseppe (1999), I Borboni di Napoli, Corbaccio, Milano.

Cremonini, Cinzia (2013), "Riequilibrare il sistema: mutazioni e permanenze in Italia tra 1706 e 1720. Alcune considerazione", Cuadernos de Historia Moderna, XII, pp. 177-188.

Cuoco, Vicenzo (1976), Saggio storico sulla rivoluzione napoletana del 1799 , Laterza, Roma-Bari. Edición de P. Villani.

D'AndreA, Diletta (2006), “Great Britain and the Mediterranean Islands in the Napoleonic Wars: The 'Insular Strategy' of Gould Francis Leckie”, Journal of Mediterranean Studies, 16, pp. 79-90.

DAVIS, John Anthony (2014), Napoli e Napoleone, L'Italia meridionale e le rivoluzioni europee (1780-1860), Soveria Mannelli, Rubbettino.

Di SAlvo, Patrizia (2013), "Propaganda, libertad de imprenta y circulación de las ideas: la influencia inglesa en el Mediterráneo (1794-1818)", Cuadernos de Historia Moderna, 38, pp. 41-72.

- (2016), Sicilia inglesa, una metáfora del constitucionalismo mediterráneo, Universidad Autónoma de Madrid, Madrid.

Ferrer Benimeli, José Antonio (2004), “El conde de Aranda y las campañas de Italia a favor de los hijos de Felipe V”, en E. SERrano Martín (coord.), Congreso internacional Felipe $V$ y su tiempo, Institución Fernando el Católico, Zaragoza, pp. 725-746.

Galasso, Giuseppe (1970), Tra Spagna e Austria, Società editrice Storia di Napoli, Napoli.

- (1992), Il Regno di Napoli. Il Mezzogiorno angioino e aragonese. (1266-1494), Storia d'Italia, XV, vol. 1, Utet, Torino.

- (2005), Il Regno di Napoli. Il Mezzogiorno spagnolo (1494-1622), Storia d'Italia, $\mathrm{XV}$, vol. 2, Utet, Torino.

- (2006), Il Regno di Napoli. Il Mezzogiorno spagnolo e austriaco (1622-1734), Storia d'Italia, XV, vol. 3, Utet, Torino.

- (2007), Il Regno di Napoli. Il Mezzogiorno borbonico e napoleonico (17341815), Storia d'Italia, XV, vol. 4, Utet, Torino.

- (2008) Il Regno di Napoli. Il Mezzogiorno borbonico e risorgimentale (18151860), Storia d'Italia, XV, vol. 5, Utet, Torino.

García Fernández, María Nélida (2006), Comerciando con el enemigo: el tráfico mercantil anglo-español en el siglo XVIII (1700-1765), CSIC, Madrid. 
Guasti, Niccolò e Russo, Saverio (2010), Il Viceregno austriaco (1707-1734). Tra capitale e province, Carocci, Roma.

Guía Marín, Lluís J. (2013), "Navegando hacia Italia. El Reino de Cerdeña en el escenario político resultante de los tratados de Utrecht-Rastatt", Cuadernos de Historia Moderna, 12, pp. 189-210.

Jover Zamora, José María (1999), España en la política internacional. Siglos XVIII-XX, Marcial Pons, Madrid.

La Parra López, Emilio (2007), "De la disputa cortesana a la crisis de la monarquía. Godoyistas y fernandinos en 1806-1807”, Cuadernos de Historia Moderna, 6, pp. 255-267.

- (2010), "Los hombres de Fernando VII en 1808", en A. Alberola, E. Larriba (eds.), Las élites y la "Revolución de España»" (1808-1814). Estudios en homenaje al profesor Gérard Dufour, Universidad, Alicante, pp. 127-152.

LaRIo de OÑate, María del Carmen (2000), La colonia mercantil británica e irlandesa en Cádiz a finales del siglo XVIII, Universidad, Cádiz.

Laspra Rodríguez, Alicia (2007), "La ayuda británica”, en A. Moliner (ed.), La Guerra de la Independencia en España (1808-1814), Nabla, Barcelona, pp. 153-184.

León SAnz, Virginia (1992) "Origen del Consejo Supremo de España en Viena", Hispania. Revista Española de Historia, II, 180, pp. 107-142.

- (2013), Carlos VI. El emperador que no pudo ser rey de España, Aguilar, Madrid.

López-Cordón Cortezo, María Victoria (1986), “Intereses económicos e intereses políticos durante la Guerra de la Independencia: las relaciones hispanorusas", Cuadernos de Historia Moderna, 8, pp. 85-106.

Martínez Carreras, José Urbano (1990), “Carlos III y África. Estado de las cuestiones", en Coloquio Internacional Carlos III y su siglo, t.1, Universidad Complutense, Madrid, pp. 915-921.

Moliner, Antonio (2007), La Guerra de la Independencia en España (1808-1814), Nabla, Barcelona.

Moñino y Redondo, José, Floridablanca, conde de (1982), “CCXC. De la Italia en general", en "Instrucción reservada que la Junta de Estado, creada formalmente por mi decreto de este día, 8 de julio de 1787 , deberá observar en todos los puntos y ramos encargados de su conocimiento y examen", en J. Ruiz Alemán (ed.), Floridablanca. Escritos políticos. La Instrucción y el Memorial, Academia Alfonso X el Sabio, Murcia.

Moreno Alonso, Manuel (1983), "Lord Holland y los orígenes del liberalismo en España", Revista de Estudios Políticos, 36, pp. 181-218.

Nava Rodríguez, María Teresa (2017), "Política, diplomacia y movilidad en la Europa napoleónica. El viaje a España de Leopoldo de Borbón, príncipe de las Dos Sicilias", en M. Bertrand, F. Andújar Castillo y T. Glesener (eds.), Gobernar y reformar la Monarquía. Los agentes políticos y administrativos en España y América (siglos XVI-XIX), Albatros, Valencia, pp. 201-214. 
Nuzzo, Giuseppe (1972), La Monarchia delle Due Sicilie tra Ancien Régime e Rivoluzione, Berisio Editore, Napoli.

- (1980), L'ascesa di Giovanni Acton al governo dello stato. Note di amicizia e dipolitica nelle lettere del re al ministro, Società Napoletana di Storia Patria, Napoli.

OchoA Brun, Miguel Ángel (1996), "Las relaciones internacionales de España, 1808-1809. Aliados y adversarios”, en II Seminario Internacional sobre la Guerra de la Independencia, Madrid, 24-26 de octubre de 1994, Ministerio de Defensa, Madrid, pp. 19-80.

OlaecheA, Rafael (1985), "Relaciones diplomáticas entre España y el reino de Nápoles a fines del '700”, en M. Di Pinto (a cura di), I Borbone di Napoli e I Borbone di Spagna, vol. 2, Guida, Napoli, pp. 7-101.

OzAnam, Didier (2002), "Dinastía, diplomacia y política exterior", en P. FERnÁndez Albaladejo (coord.), Los Borbones. Dinastía y memoria de la España del siglo XVIII, Casa de Velázquez, Marcial Pons, Madrid, pp. 17-46.

Palumbo, Raffaele (1999), Carteggio di Maria Carolina regina delle Due Sicilie con lady Emma Hamilton. Documenti inediti, Pironti, Napoli.

Pascerini, María Cristina (2016), "La diplomacia secreta durante las guerras de Cerdeña y Sicilia: el papel de Giulio Alberoni como ministro de España y agente del ducado de Parma y Plasencia", Vegeta. Anuario de la Universidad de las Palmas de Gran Canaria, 16, pp. 245-263.

Pérez SAMPer, María Ángeles (2003), Isabel de Farnesio, Plaza \& Janés, Barcelona. Petraccone, Claudia (1984), "Il giacobinismo napoletano", en M. L. Salvadori, $\mathrm{N}$, Tranfaglia (a cura di), Il mondo contemporaneo. Il modelo politico giacobino e le rivoluzioni, La Nuova Italia, Firenze, pp. 132-153.

- (1989), Napoli nel 1799. Rivoluzione e proprietà, Morano, Napoli.

Pontieri, Ernesto (1932), Il marchese Caracciolo viceré di Sicilia e il ministro Acton. Lettere inedite sul Governo di Sicilia, 1782-1786, Cooperativa tip. Sanitaria, Napoli.

Pradells Nadal, Jesús (1991), "Los cónsules españoles del siglo XVIII: caracteres profesionales y vida cotidiana", Revista de Historia Moderna. Anales de la Universidad de Alicante, 10, pp. 209-262.

- (1992), Diplomacia y comercio, la expansión consular española en el siglo XVIII, Universidad, Alicante.

- (1990), "Una fuente infrautilizada: la documentación consular española del siglo XVIII", en Coloquio Internacional Carlos III y su siglo, vol. 1, Universidad Complutense, Madrid, pp. 895-913.

- (1996), "La diplomacia y los diplomáticos españoles en la Guerra de la Independencia”, en II Seminario Internacional sobre la Guerra de la Independencia, Madrid, 24-26 de octubre de 1994, Ministerio de Defensa, Madrid, pp. 81-124.

Rao, Anna María (2003), "Manuel Godoy e l'Italia”, en M. A. Melón, E. La Parra y F. Tomás Pérez (eds.), Manuel Godoy y su tiempo, t.1, Editorial Regional de Extremadura, Mérida, pp. 587-605. 
ReCCA, Cinzia (2014a), "Maria Carolina and Marie Antoinette. Sisters and queens in the mirror of Jacobin public opinion", Royal Studies Journal, 1, pp. 17-36.

- (2014b), Sentimenti e política. Il diario inedito della regina Maria Carolina di Napoli (1781-1785), Franco Angeli.

RendA, Francesco (2011), Maria Carolina e Lord Bentinck nel diario di Luigi de' Medici, Sellerio editore, Palermo.

Molas Ribalta, Pere (2003), "La red Godoy”, en M. Á. Melón, E. La Parra y F. Tomás Pérez (eds.), Manuel Godoy y su tiempo, t.1, Editorial Regional de Extremadura, Mérida, pp. 361-379.

Romano, Andrea (1998), Il modelo costituzionale inglese e la sua recezione nell'area mediterranea tra la fine del settecento e la prima metà dell'ottocento, Giuffrè, Milano.

SCANDELlari, Simonetta (2008), "El Settecento italiano: del reformismo a la República", Cuadernos de Historia Moderna, Anejos, VII, pp. 91-114.

Schroeder, Paul W. (1994), The transformation of European Politics 1763-1848, University Press, Oxford.

Stampa Piñeiro, Leopoldo (2011), Pólvora, plata y boleros. Memorias de testigos y combatientes en la Guerra de la Independencia, Marcial Pons, Madrid.

Torre Fernández del Pozo, Servando de la (2007), "Fuentes para el estudio de la Guerra de la Independencia. La Europa de 1807-1808 vista por el Embajador austriaco en París: Metternich y sus memorias", Cuadernos de Historia del Derecho, 14, pp. 189-206.

Varela Suanzes-Carpegna, Joaquín (2013), La monarquía doceañista (1810-1837), Marcial Pons, Madrid.

VÁzquez Gestall, Pablo (2008), Corte, poder y cultura política en el reino de las Dos Sicilias de Carlos de Borbón (1734-1759), Universidad Complutense, Madrid. Tesis doctoral.

Verga, Marcello (1985), "Il “sogno spagnolo" di Carlo VI. Alcune considerazioni sulla monarchia asburgica e i domini italiano nella prima metà del Settecento", en C. Mozzarelli e G. Olmi (eds.), Il Trentino nel Settecento tra Sacro Romano Impero e antichi stati italiani, Il Mulino, Bologna, pp. 203-261. 